\title{
Interleukin 17-producing T helper cells and interleukin 17 orchestrate autoreactive germinal center development in autoimmune BXD2 mice
}

\author{
Hui-Chen Hsu ${ }^{1}$, PingAr Yang ${ }^{1}$, John Wang ${ }^{1}$, Qi Wu ${ }^{1}$, Riley Myers ${ }^{1}$, Jian Chen ${ }^{1}$, John $\mathrm{Yi}^{2}$, Tanja Guentert ${ }^{1}$, \\ Albert Tousson $^{3}$, Andrea L Stanus ${ }^{4}$, Thuc-vy L Le ${ }^{2}$, Robin G Lorenz ${ }^{4}$, Hui Xu ${ }^{5}$, Jay K Kolls ${ }^{6}$, \\ Robert H Carter ${ }^{1,7}$, David D Chaplin ${ }^{2}$, Robert W Williams ${ }^{8}$ \& John D Mountz ${ }^{1,7}$
}

Interleukin 17 (IL-17) is a cytokine associated with inflammation, autoimmunity and defense against some bacteria. Here we show that IL-17 can promote autoimmune disease through a mechanism distinct from its proinflammatory effects. As compared with wild-type mice, autoimmune BXD2 mice express more IL-17 and show spontaneous development of germinal centers (GCs) before they increase production of pathogenic autoantibodies. We show that blocking IL-17 signaling disrupts CD4 ${ }^{+}$T cell and B cell interactions required for the formation of GCs and that mice lacking the IL-17 receptor have reduced GC B cell development and humoral responses. Production of IL-17 correlates with upregulated expression of the genes Rgs13 and Rgs16, which encode regulators of G-protein signaling, and results in suppression of the B cell chemotactic response to the chemokine CXCL12. These findings suggest a mechanism by which IL-17 drives autoimmune responses by promoting the formation of spontaneous GCs.

Much evidence shows that IL-17 promotes autoimmune disease and has a role in the development of rheumatoid arthritis, multiple sclerosis, inflammatory bowel disease and psoriasis $^{1-4}$. Studies indicate that IL-17-producing T-helper $\left(\mathrm{T}_{\mathrm{H}^{-}}\right.$-17) cells constitute a distinct $\mathrm{CD}^{+} \mathrm{T}$ helper effector cell population that differs in function and phenotype from the classical $\mathrm{T}$ helper type $1\left(\mathrm{~T}_{\mathrm{H}} 1\right)$ and $\mathrm{T}_{\mathrm{H}} 2$ populations ${ }^{5-7}$. Initially, IL-17 was described as a potent proinflammatory cytokine that acts on fibroblast, stromal, epithelial and endothelial cells and some monocytes to stimulate the secretion of other proinflammatory mediators, such as the chemokine ligand CXCL8 (also known as IL-8), CXCL1 (also known as GRO $\alpha$ ), tumor necrosis factor (TNF) and granulocyte colony-stimulating factor ${ }^{1}$. Collectively, these effects contribute to a generalized stimulation of the inflammatory response. IL-17 is linked to the induction of autoreactive humoral immune responses because a deficiency in or blockade of this chemokine is associated with a decline in the autoantibody response $e^{8-10}$. The mechanism by which IL-17 induces autoreactive humoral responses has not been elucidated.

The BXD2 recombinant inbred mouse is one of several strains generated by inbreeding the intercross progeny of C57BL/6J and DBA/2J mice for more than 20 generations ${ }^{11}$. We previously used BXD2 with 19 other recombinant inbred strains of BXD mice in a survey of genetic loci that may influence $T$ cell senescence ${ }^{12}$. In those studies, we noted that the BXD2 mice develop a spontaneous erosive arthritis that progresses as the mice age $\mathrm{e}^{12,13}$. Further analysis established that the mice show other hallmarks of autoimmune disease, including increasing titers of circulating immune complexes and the progressive development of glomerulonephritis ${ }^{14,15}$. Throughout the lifetime of BXD2 mice, the autoantibody repertoire undergoes constant alteration, and the onset of both kidney and joint diseases correlates with an increase in titers of circulating immune complexes ${ }^{14}$. The symptoms of autoimmune disease also correlate with rising titers of autoantibodies that target nucleosome proteins, metabolic enzymes, structural proteins and heat shock proteins ${ }^{14}$. Through the production and analysis of several hybridoma clones from a BXD2 mouse with both arthritis and renal disease, we previously established that individual autoantibodies can elicit pathogenic responses on adoptive transfer to naive non-autoimmune mice and that these autoantibodies can cause autoimmune disease independently of $\mathrm{CD}^{+} \mathrm{T}$ cell activity ${ }^{14}$.

The pathogenic potential of the monoclonal autoantibodies correlates with their ability to recognize several autoantigens ${ }^{14}$. In addition, sequencing of the pathogenic autoantibodies indicated that somatic hypermutation (SHM) and class-switch recombination are enhanced in BXD2 mice ${ }^{15}$. The $\mathrm{B}$ cells of BXD2 mice overexpress

\footnotetext{
${ }^{1}$ Departments of Medicine, ${ }^{2}$ Microbiology, ${ }^{3}$ Cell Biology, ${ }^{4}$ Pathology and ${ }^{5}$ Dermatology, University of Alabama at Birmingham, Birmingham, Alabama 35294, USA. ${ }^{6}$ Pediatric Pulmonology, Children's Hospital of Pittsburgh, Pittsburgh, Pennsylvania 15213, USA. ${ }^{7}$ Birmingham VA Medical Center, Birmingham, Alabama 35233, USA. ${ }^{8}$ Department of Anatomy and Neurobiology, University of Tennessee at Memphis, Memphis, Tennessee 38152, USA. Correspondence should be addressed to H.-C.H. (huichen.hsu@ccc.uab.edu) or J.D.M. (john.mountz@ccc.uab.edu).
} 
activation-induced cytidine deaminase (AICDA), which can be induced by a CD28 co-stimulatory signal provided by the $\mathrm{CD} 4^{+}$ $\mathrm{T}$ cells of these mice ${ }^{15}$. Administration of a single dose of an adenovirus expressing the CD28 antagonist CTLA4-Ig before the onset of disease in BXD2 mice leads to chronic suppression of Aicda expression in B cells, which is associated with long-term suppression of the development of autoantibodies ${ }^{15}$. These results suggest that an interaction between the $\mathrm{CD}^{+} \mathrm{T}$ cells and $\mathrm{B}$ cells of BXD2 mice is essential for the development of pathogenic autoantibodies, a conclusion that is further supported by the enhanced cycling of GC B cells that express large amounts of CD86 in these mice ${ }^{15}$.

GCs are specialized foci of cells that facilitate antigen presentation and $\mathrm{T}$ and $\mathrm{B}$ cell interactions during normal immune responses ${ }^{16-19}$. They can arise spontaneously in the spleen, in the lymph nodes or at ectopic sites in autoimmune disease $\mathrm{e}^{20-22}$, and these spontaneous GCs can be a site of production of autoantibodies such as rheumatoid factor and anti-DNA ${ }^{20-22}$. The assembly of the GCs requires regulation of $\mathrm{B}$ and $\mathrm{T}$ cell migration, including attracting $\mathrm{B}$ and $\mathrm{T}$ cells into the GCs, organizing them within GCs, and orchestrating their egress from GCs at appropriate developmental stages ${ }^{18,23}$. The primary chemokines involved in antigen-induced GC formation are CXCL12 and CXCL13, which signal through the G-coupled protein receptors CXCR4 and CXCR5, thereby regulating $\mathrm{B}$ and $\mathrm{T}$ cell migration ${ }^{16,17}$. Regulators of G-protein signaling (RGS) proteins, which accelerate the intrinsic rate of the G $\alpha$ GTPase reaction ${ }^{24-26}$, can downregulate the response of lymphocytes to these chemokines, thus retarding migration of the cells. It has been reported that GC $\mathrm{CD}^{+}{ }^{+} \mathrm{T}$ cells express primarily RGS16 and that GC B cells express RGS1, RGS13 and RGS16 (refs. 27-29).

Here we report that in autoimmune BXD2 mice IL-17 is the most prominent spontaneously increased $\mathrm{T}_{\mathrm{H}}$ cell-associated cytokine; in addition, the percentage of $\mathrm{T}_{\mathrm{H}^{-}} 17$ cells in the spleen is higher in $\mathrm{BXD} 2$ mice than in wild-type mice, and $\mathrm{B}$ cells express large amounts of the IL-17 receptor (IL-17R). In the spleens of BXD2 mice, $\mathrm{T}_{\mathrm{H}^{-}}-17$ cells and the $\mathrm{B}$ cells that express large amounts of IL-17R are in close proximity and form well-defined GCs. We show that pretreatment of B cells with IL-17 in vitro reduces their chemotactic response to CXCL12 and CXCL13 through a mechanism associated with enhanced abundance of Rgs13 and Rgs16 mRNA. Administration of an adenovirus encoding IL-17 (AdIL-17) in vivo results in the formation of GCs and in enhanced expression of Rgs13, Rgs16 and Aicda mRNAs, whereas blockade of IL-17 function by an inhibitory adenovirus construct (AdIL-17R:Fc) or by using B cells from $I l 17 r^{-/-}$BXD2 mice inhibits these features. Collectively, our results suggest that $\mathrm{T}_{\mathrm{H}^{-1}}-\mathrm{T}$ cells and IL-17 orchestrate the spontaneous formation of autoreactive GCs by arresting the migration of $\mathrm{B}$ cells. We propose that this arrest of migration stabilizes these autoreactive GCs, thereby providing an optimal microenvironment for the upregulation of AICDA and the generation of pathogenic autoantibodies.

\section{RESULTS}

\section{Enhanced development of $\mathrm{T}_{\mathrm{H}^{-}}-17 \mathrm{~T}$ cells in BXD2 mice}

We previously found that in BXD2 mice the production of pathogenic autoantibodies that have undergone extensive SHM and class-switch recombination is associated with upregulation of Aicda in the GC $\mathrm{B}$ cells and that this upregulation of Aicda in the B cells is linked to $\mathrm{CD}^{+}{ }^{+} \mathrm{T}$ cell activity ${ }^{15}$. We therefore wanted to identify the cytokines and the specific lineage of $\mathrm{CD}^{+} \mathrm{T}$ cells that contribute to the enhanced expression of Aicda and the production of autoantibodies. We found that, although the serum concentrations of IFN- $\gamma$ and IL-4 were similar in BXD2 mice and age-matched B6 mice, 6-monthold BXD2 mice had significantly more circulating IL-17 than did 6-month-old B6 mice (Fig. 1a). Subsequent analysis of the percentages of $\mathrm{T}_{\mathrm{H}^{-}} 17 \mathrm{CD}^{+} \mathrm{T}$ cells, IFN- $\gamma$-producing $\mathrm{T}_{\mathrm{H}} 1$ cells and IL-4-producing $\mathrm{T}_{\mathrm{H}} 2 \mathrm{CD}^{+} \mathrm{T}$ cells indicated a significantly higher percentage of $\mathrm{T}_{\mathrm{H}^{-}} 17 \mathrm{CD}^{+} \mathrm{T}$ cells, but not IFN- $\gamma$-producing $\mathrm{T}_{\mathrm{H}} 1$ cells or IL-4producing $\mathrm{T}_{\mathrm{H}} 2 \mathrm{CD}^{+} \mathrm{T}$ cells, in the spleens of BXD2 mice than in the spleens of age-matched B6 mice (Fig. 1b). The higher expression of Il17 transcripts in spleen $\mathrm{CD}^{+} \mathrm{T}$ cells from BXD2 mice was confirmed by quantitative PCR (qPCR; Fig. 1c). The qPCR analysis also showed higher abundance of $I l 17 r$ transcripts in $\mathrm{B} 220^{+} \mathrm{B}$ cells purified from the spleens of BXD2 mice than in those purified from the spleens of age-matched B6 mice (Fig. 1c).

To determine whether the BXD2 spleen fosters a polarization toward $\mathrm{T}_{\mathrm{H}^{-}} 17$ cells, we cultured purified $\mathrm{CD} 4^{+} \mathrm{T}$ cells or unfractionated spleen cells on irradiated feeder cells under conditions known to promote the in vitro polarization of $\mathrm{CD}^{+} \mathrm{T}$ cells - that is, in the presence of neutralizing antibodies to IFN- $\gamma$ (anti-IFN- $\gamma$ ) and antiIL-4, in addition to IL-23, IL- 6 and TGF- $\beta$ (refs. 5,6). Under these conditions, $\mathrm{T}_{\mathrm{H}^{-}} 17$ cells developed from the $\mathrm{CD} 4^{+} \mathrm{T}$ cells and from the unfractionated spleen preparations from $\mathrm{B} 6$ mice, and the development of $\mathrm{T}_{\mathrm{H}^{-}} 17$ cells from purified $\mathrm{CD}^{+} \mathrm{T}$ cells under both
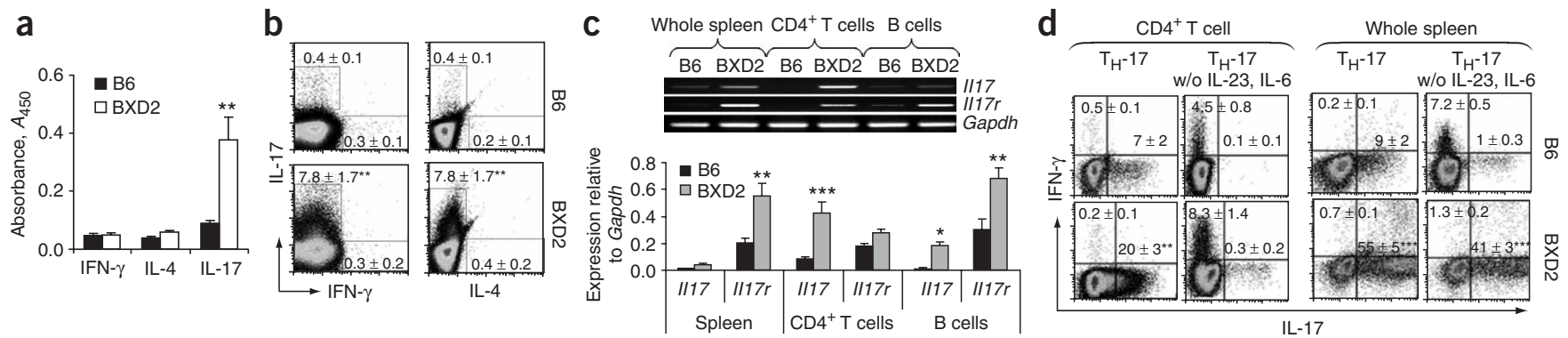

Figure 1 Enhanced development of $\mathrm{T}_{\mathrm{H}}-17$ cells in BXD2 mice. (a) ELISA of IFN- $\gamma$, IL-4 and IL-17 in sera from 6-month-old B6 and BXD2 mice. $* * P<0.01$ ( $n=5$ mice per group). (b) Flow cytometry analysis of intracellular IL-17 and IFN- $\gamma$ (left) or intracellular IL-17 and IL-4 (right) in spleen cells from 6-month-old B6 or BXD2 mice. Cells were gated on CD4. ${ }^{*} P<0.01$. (c) Top, quantitative RT-PCR analysis of $/ / 17$, $/ / 17 r$ and control Gapdh in MACS-purified CD4 ${ }^{+} \mathrm{T}$ cells and B220 $\mathrm{B}$ cells from 6-month-old B6 or BXD2 mice. Below, expression of $/ / 17$ and $/ / 17$ r relative to Gapdh. ${ }^{* *} P<0.01$; $* * * P<0.005$. (d) Flow cytometry analysis of IFN- $\gamma$ and IL-17 in purified CD4 ${ }^{+} \mathrm{T}$ cells (left) or whole spleen cells (right) from 3-month-old B6 mice or BXD2 mice. The cells were cultured in vitro for $5 \mathrm{~d}$ with anti-CD3 plus anti-IFN- $\gamma$, anti-IL-4 and TGF- $\beta$ in the presence (left) or absence (right) of IL-6 and IL-23 for $5 \mathrm{~d}$. The cells were then stimulated with PMA plus ionomycin in the presence of GolgiPlug and permeabilized before analysis. ** $P<0.01$; ${ }^{* * *} P<0.005$. Data are representative of five (b) or four (d) experiments, or are the mean \pm s.e.m. of five (a) or three independent experiments (c). 
Figure 2 Formation of spontaneous GCs and localization of $T_{H^{-}} 17$ cells and IL-17R ${ }^{+} B$ cells in the spleen. (a-h) Immunofluorescence microscopy of frozen tissue sections from the spleens of naive 6-month-old BXD2 (a,c,e-g) and B6 (b,d,h) mice. Sections were stained with PNA (blue), anti-IgM (B, red), anti-CD35 (white) and anti-CD4 (T, yellow; a,b); with anti-IL-17 (red), anti-B220 or PNA (blue), and anti-CD4 (yellow; c-e); or with anti-IL-17R (yellow), PNA (blue) and anti-IgM (red; f-h). Scale bar, $100 \mu \mathrm{m}$. FDC, follicular dendritic cell; $M Z$, marginal zone; MS, marginal sinus. Magnification, $\times 20(\mathbf{a}-\mathbf{d}, \mathbf{f}, \mathbf{h})$ and $\times 40(\mathbf{e}, \mathbf{g})$ of the objective lens used for acquiring each image. Data are representative of the results obtained for analysis of spleen tissue from at least three BXD2 and three age-matched B6 mice.

conditions required the addition of IL- 6 and IL-23 (Fig. 1d, top). Significantly more $\mathrm{T}_{\mathrm{H}^{-}} 17$ cells developed from enriched $\mathrm{CD}^{+}$ $\mathrm{T}$ cells and from the unfractionated spleen preparations from BXD2 mice as compared with B6 mice. Supplementary IL-6 and IL-23 were not required for the development of $\mathrm{T}_{\mathrm{H}^{-1}} 17 \mathrm{CD}^{+} \mathrm{T}$ cells from the unfractionated BXD2 spleen cells, but were required for their development from the purified $\mathrm{CD}^{+} \mathrm{T}$ cells (Fig. 1d, bottom). This result suggests that cells in the cultures of unfractionated spleen cells from BXD2 mice are producing IL- 6 and IL-23. Consistent with this, we observed strong induction of IL- 6 by BXD2 spleen cells after in vitro stimulation with lipopolysaccharide (LPS), and we found that high Il23 mRNA expression occurred in non-CD4 T cells, non-B cells freshly isolated from the spleens of BXD2 mice (Supplementary Fig. 1 online). Taken together, these results suggest that the production of large amounts of IL-6 and IL-23 in the spleens of BXD2 mice is important for the enhanced development of $\mathrm{T}_{\mathrm{H}^{-17}} \mathrm{~T}$ cells.

\section{Localization of $\mathrm{T}_{\mathrm{H}^{-}} \mathbf{1 7}$ cells and IL-17R+ $\mathrm{B}$ cells}

In the analysis of the spleens of 6-month-old BXD2 mice, we noted several large, well-formed GCs (Fig. 2a), which were not present in age-matched B6 mice (Fig. 2b). The number and size of the GCs were
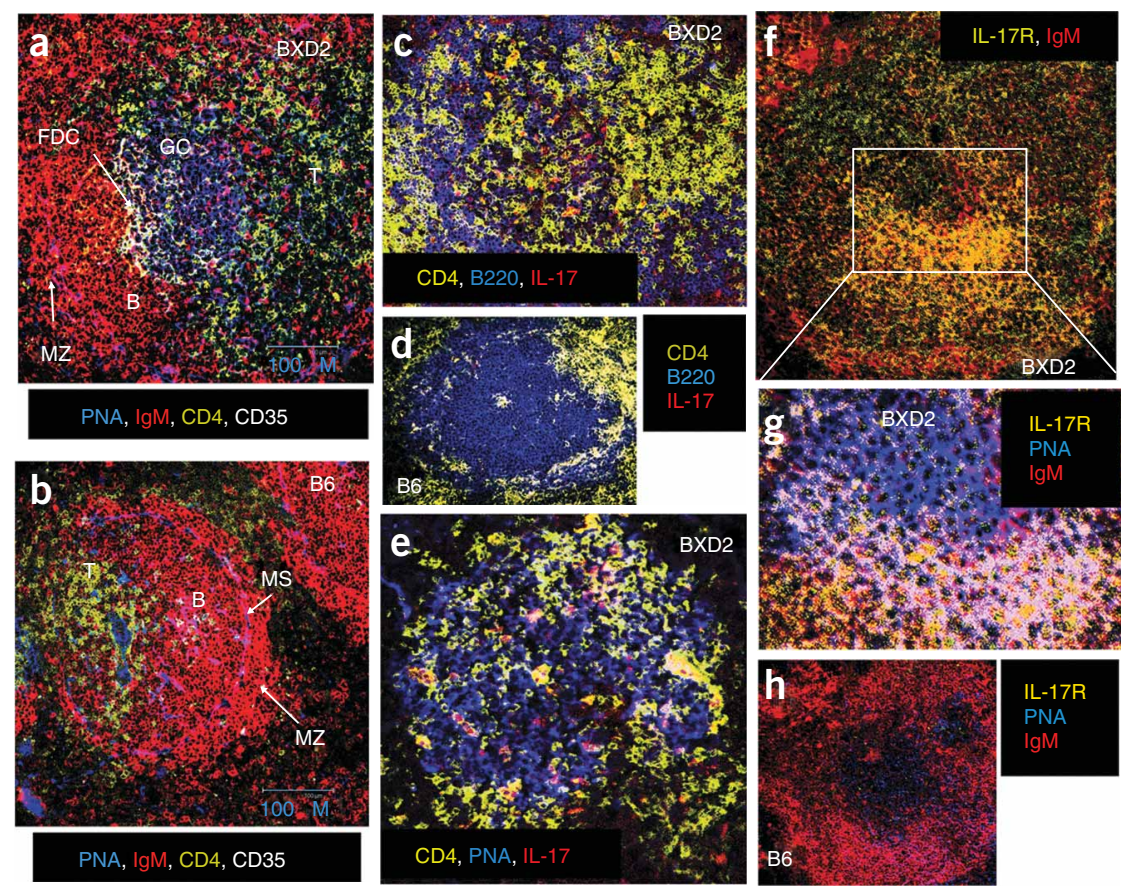

quantified by using a confocal microscopy grid system (Supplementary Fig. 2 online). The average number of GCs per $\mathrm{mm}^{2}$ of area in the spleens of 6-month-old BXD2 mice was tenfold higher than that in age-matched B6 mice $\left(4.1 \pm 0.22\right.$ versus $0.4 \pm 0.10 \mathrm{GCs}$ per $\mathrm{mm}^{2}$, $P<0.005$; Supplementary Fig. 2). Quantification of the area of peanut agglutinin-positive $\left(\mathrm{PNA}^{+}\right) \mathrm{GC}$ cells as a percentage of the spleen section area $\left(\mathrm{mm}^{2}\right)$ indicated that the proportion of GC cells was nearly 18-fold higher in 6-month-old BXD2 mice than in agematched B6 mice $(10.5 \pm 1.2$ versus $0.58 \pm 0.22 ; P<0.001$; Supplementary Fig. 2). FACS analysis indicated that there was not only higher cellularity but also greater percentages of $\mathrm{PNA}^{+} \mathrm{Fas}^{+} \mathrm{CD} 19^{+}$ GC B cells in the spleens of the BXD2 mice as compared with agematched ( $\geq 3$-month-old) B6 mice (Supplementary Table 1 online).

Analysis of the expression of IL-17 indicated that there were more $\mathrm{IL}-17^{+}$cells, most of which expressed CD4, in the spleens of BXD2

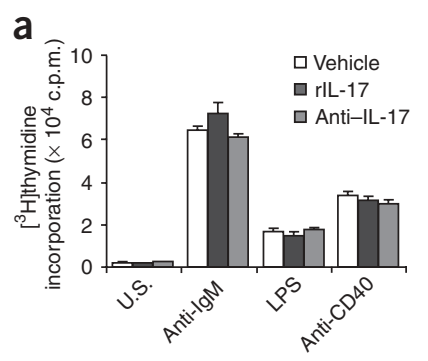

b

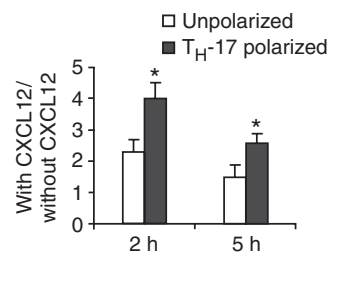

C

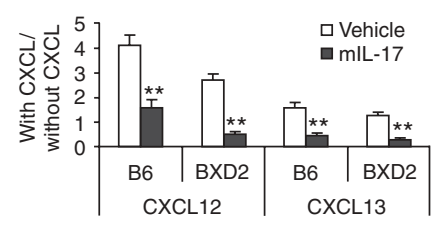

d
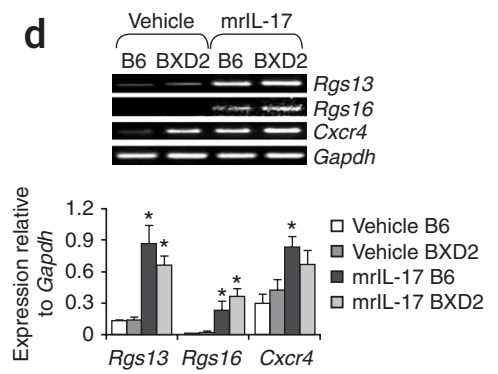

Figure 3 IL-17 modifies chemotaxis and induces Rgs13 and Rgs16 expression in B cells. (a) Proliferation assay of MACS-purified B cells from 3-month-old BXD2 mice. Cells were cultured with recombinant IL-17 $(20 \mathrm{ng} / \mathrm{ml})$ or anti-IL-17 $(10 \mu \mathrm{g} / \mathrm{ml})$ in medium alone (unstimulated, U.S.) or with anti-lgM $(10 \mu \mathrm{g} / \mathrm{ml})$, LPS $(10 \mu \mathrm{g} / \mathrm{ml})$ or anti-CD40 $(10 \mu \mathrm{g} / \mathrm{ml})$. After $72 \mathrm{~h}$, proliferation was measured by a standard $\left[{ }^{3} \mathrm{H}\right]$ thymidine incorporation assay. (b) Chemotactic response of unpolarized or $\mathrm{T}_{\mathrm{H}}$-17-polarized T cells from 3-month-old B6 or BXD2 mice to CXCL12. Cells were analyzed using a Transwell migration chamber with CXCL12 $(100 \mathrm{ng} / \mathrm{ml})$ or culture medium in the bottom chamber; $\mathrm{T}_{\mathrm{H}^{-}} 17$ polarization was carried out as in Figure 1 . ${ }^{*} P<0.05$. (c) Chemotactic response of MACS-purified CD19+ B cells from 3-month-old B6 or BXD2 mice to CXCL12 and CXCL13. Cells were cultured in the presence of recombinant mouse IL-17 (20 ng/ml) for $4 \mathrm{~h}$, and then their migration in response to chemokine was analyzed after $2 \mathrm{~h}$. ${ }^{* *} P<0.01$. (d) Top, quantitative RT-PCR analysis of Rgs13, Rgs16 and Cxcr4 mRNA in MACS-purified B cells from B6 or BXD2 mice after culture for $4 \mathrm{~h}$ with IL-17. Bottom, expression relative to control Gapdh mRNA. ${ }^{*} P<0.05$. Data are the mean \pm s.e.m. of 3 experiments with 2 replicates in each (a), or are representative of three independent experiments $(\mathbf{b}-\mathbf{d})$. 
a
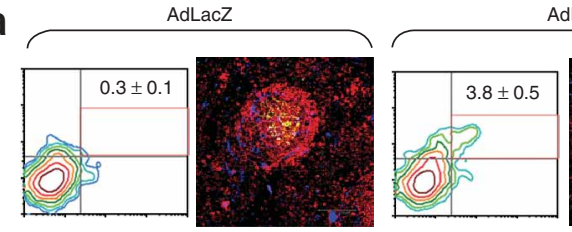

AdIL-17
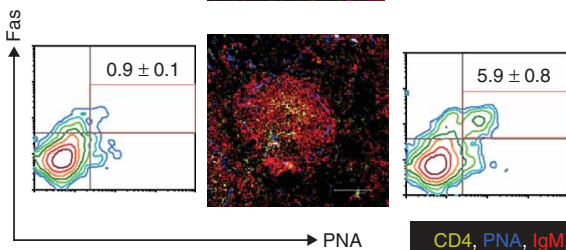

$\mathrm{CD} 4$, b

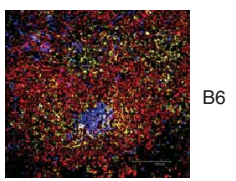

B6

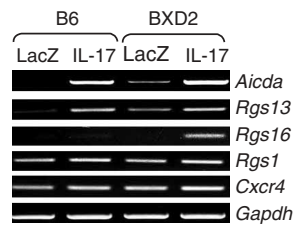

Figure 4 Induction of GCs in vivo on administration of IL-17. (a) Flow cytometry analysis and immunofluorescence microscopy of GCs in the spleens of young (1-month-old) B6 and BXD2 mice treated with AdIL-17 or AdLacZ ( $10^{9}$ viral particles per mouse, i.v.). The spleens were obtained $10 \mathrm{~d}$ after injection. Single-cell suspensions were prepared and the percentage of GC B cells was determined by flow cytometry of $\mathrm{Fas}^{+} \mathrm{PNA}^{+}$cells in the $\mathrm{B} 220^{+}$population. ${ }^{* *} P<0.01$. Right, frozen sections of spleens stained with anti-mouse CD4 (yellow), PNA (blue), anti-IgM (red) and anti-mouse CD35 (white). (b) RT-PCR analysis of Aicda, Rgs13, Rgs 16, Rgs 1, Cxcr4 and Gapdh mRNA in the spleens of mice in a. (c) ELISA of IgM and IgG autoantibodies specific for DNA or histone in sera from young (1-month-old) B6 and BXD2 mice treated with AdIL-17 or AdLacZ as in a. Samples of sera obtained at the indicated time points for up to 3 months after injection were analyzed by isotype-specific ELISA. Data are representative of three experiments $(\mathbf{a}, \mathbf{b})$, or are the mean \pm s.e.m. of three independent experiments (c).
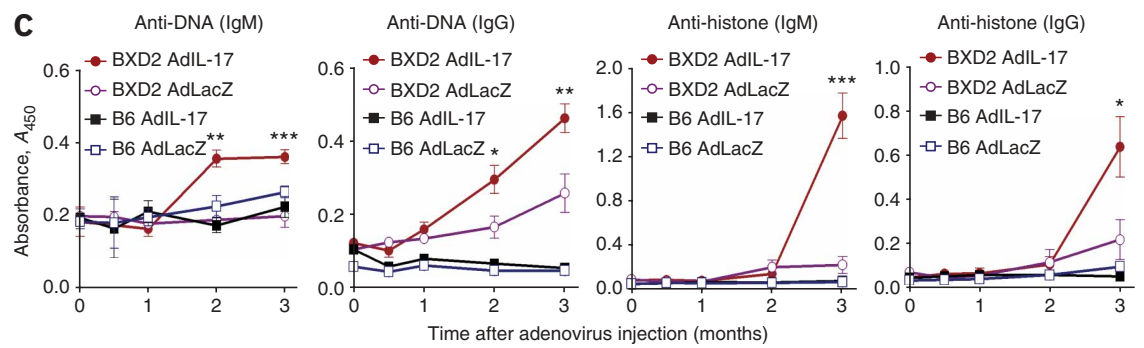

mice (Fig. 2c) than in those of age-matched B6 mice (Fig. 2d). These $\mathrm{T}_{\mathrm{H}^{-}} 17$ cells were predominantly localized near the $\mathrm{PNA}^{+} \mathrm{GC}$ region in BXD2 mice (Fig. 2e). Similarly, analysis of the expression of IL-17R in the spleens of BXD2 mice confirmed that there were more IL-17R ${ }^{+}$ cells, which were primarily in the follicles (Fig. 2f). We identified $\mathrm{IgM}^{+} \mathrm{B}$ cells that coexpressed IL-17R specifically in regions of the GC in close proximity to the $\mathrm{PNA}^{+} \mathrm{B}$ cells (Fig. 2g, white); we also identified $\mathrm{PNA}^{+} \mathrm{IgM}^{-} \mathrm{B}$ cells that coexpressed IL-17R (Fig. 2g, pink). Very few IL- $17 \mathrm{R}^{+}$cells were detected in the spleens of $\mathrm{B} 6$ mice (Fig. 2h).

\section{IL-17 inhibits chemotaxis and upregulates Rgs 13 and Rgs16}

The proximity of the B cells expressing IL-17R to the T cells producing IL-17 in the spleens of the BXD2 mice suggested that IL-17 could be acting either by itself or as a co-stimulatory signal to induce proliferation of the B cells. The BXD2 B cells, however, showed only a low proliferation rate on day 3 of in vitro culture, and this rate was not altered significantly either by the addition of IL-17 $(20 \mathrm{ng} / \mathrm{ml})$ or by neutralization of IL-17 with anti-IL-17 ( $P>0.1, n=3$; Fig. 3a). Similarly, the proliferative response of the BXD2 B cells to antiIgM, LPS or anti-CD40 was unaffected by the addition of IL-17 or anti-IL-17 (Fig. 3a). Thus, in BXD2 mice, the engagement of IL-17R by IL-17 does not seem to alter the kinetics of the B cell proliferative response.

An alternative possibility was that $\mathrm{T}_{\mathrm{H}^{-}} 17$ cells, or the IL-17 produced by these cells, might promote the formation of GCs. Specifically, the $\mathrm{T}_{\mathrm{H}^{-17}}$ cells could either foster the recruitment of other $\mathrm{T}_{\mathrm{H}^{-17}}$ cells or IL-17R $\mathrm{R}^{+} \mathrm{B}$ cells to the GCs or promote their retention within the GCs. The interaction of CXCL12 with CXCR4 expressed on $\mathrm{B}$ and $\mathrm{T}$ cells has an important role in the antigen-driven development of GCs ${ }^{16,29,30}$. To determine whether CXCL12 might function to recruit $\mathrm{T}_{\mathrm{H}^{-}} 17 \mathrm{CD} 4^{+} \mathrm{T}$ cells, we polarized $\mathrm{CD} 4^{+} \mathrm{T}$ cells from BXD2 mice and analyzed their migration toward CXCL12 in a Transwell migration chamber. The polarized $\mathrm{T}_{\mathrm{H}^{-}} 17$ cells showed a significantly higher chemotactic response to CXCL12 than did the unpolarized CD4 ${ }^{+} \mathrm{T}$ cells (Fig. $3 \mathbf{b}$ ).
We determined the effects of IL-17 on the migration of B cells in response to CXCL12. In these experiments, B cells from the spleens of B6 and BXD2 mice were cultured with IL-17 or control medium for $4 \mathrm{~h}$ and then placed in the upper well of a Transwell migration chamber with CXCL12 or control medium in the lower chamber; after $2 \mathrm{~h}$, the ratio of $\mathrm{B}$ cells in the lower chamber relative to the upper chamber was determined. Unexpectedly, pretreatment with IL-17 reduced the Transwell migration response of the B cells to CXCL12 (Fig. 3c); this inhibitory effect was observed irrespective of whether the B cells were obtained from BXD2 or B6 mice. Similar results were obtained with CXCL13 (Fig. 3c). Further analysis indicated that this IL-17-induced inhibition of the chemotactic response was not associated with a reduction in the expression of Cxcr4 mRNA encoding the CXCL12 receptor in either the BXD2 or the B6 B cells, but was associated with an upregulation of $\mathrm{Rgs} 13$ and $\mathrm{Rgsl6}$ mRNAs (Fig. 3d).

\section{IL-17 induces GC development in vivo}

To determine directly whether IL-17 can promote GC formation in vivo, we injected 1-month-old $\mathrm{B} 6$ and $\mathrm{BXD} 2$ mice with the adenovirus construct AdIL-17 ( $10^{9}$ plaque-forming units (p.f.u.) per mouse), which enhances the concentrations of circulating IL-17 (ref. 31); as a control, we injected littermate B6 and BXD2 mice with an adenovirus vector that expresses $\beta$-galactosidase (AdLacZ). The amount of circulating IL-17 in untreated BXD2 mice at 1 month of age is low and equivalent to that in untreated B6 mice of the same age. FACS analysis indicated that, in both BXD2 and B6 mice, administration of AdIL-17 resulted in higher percentages of $\mathrm{PNA}^{+} \mathrm{Fas}^{+}$ GC B cells as compared with mice treated with AdLacZ (Fig. 4a and Supplementary Table 1). We also observed higher numbers of $\mathrm{PNA}^{+}$ GC B cells by in situ analysis of the spleens of both B6 and BXD2 mice after AdIL-17 injection, suggesting that IL-17 promotes the formation of GCs and can do so in both autoimmune BXD2 mice and nonautoimmune, naive B6 mice. Increased abundance of $\operatorname{Rgs} 13$ mRNA was observed in the spleens of both strains (Fig. $\mathbf{4 b}$ and Supplementary Table 2). The amount of Rgs16 mRNA was lower in 
a
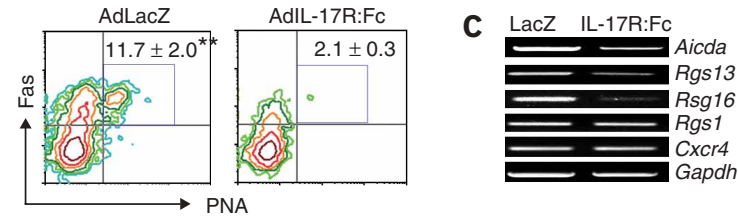

b

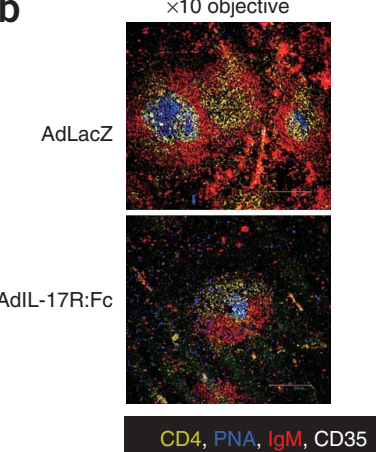

$\times 40$ objective

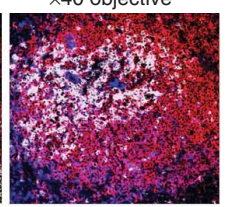

B6 mice than in BXD2 mice (Fig. 4b). Neither strain showed differences in the abundance of Rgs1 or Cxcr4 mRNA after administration of AdIL-17.

Administration of AdIL-17 also increased the abundance of Aicda mRNA in the spleens of both strains (Fig. $4 \mathbf{b}$ and Supplementary Table 2). In addition, administration of AdIL-17 to 1-month-old BXD2 mice accelerated the subsequent development of IgM and IgG anti-DNA and histone autoantibodies (Fig. 4c). Although administration of AdIL-17 to B6 mice resulted in higher numbers of GC B cells and induced Rgs13 transcription, it did not stimulate the development of autoantibodies in these mice (Fig. 4c).

Collectively, these data suggest that IL-17 can promote the formation of GCs in both BXD2 and B6 mice. This process is sufficient to accelerate the development of autoantibody-producing GCs in the spleens of autoimmune-prone BXD2 mice; however, it does not induce the formation of autoantibody-producing GCs in the spleens of nonautoimmune B6 mice, suggesting that other signals are required.

\section{IL-17 is required to stabilize developed GCs}

Reasoning that the duration, and thus the extent, of the interaction between the B and T cells in the GCs is most probably involved in fostering the production of autoantibodies by the B cells, we sought to determine whether IL-17 is required to maintain the integrity of the spontaneously formed GC-like structures in BXD2 mice. We therefore treated 10-month-old BXD2 mice with an adenovirus construct to neutralize IL-17 (AdIL-17R:Fc; $10^{9}$ p.f.u. per mouse). At 10 months of age, BXD2 mice have large amounts of serum IL-17 and high numbers of spontaneously formed GCs in the spleen. Ten days after administration of the adenovirus, there were markedly fewer $\mathrm{Fas}^{+} \mathrm{PNA}^{+} \mathrm{GC}$ $\mathrm{B}$ cells in the spleens of AdIL-17R:Fc-treated BXD2 mice than in those of the control, AdLacZ-treated BXD2 mice (Fig. 5a and Supplementary Table 1).

The GC structures in AdLacZ-treated BXD2 mice consisted of accumulations of $\mathrm{CD}^{+} \mathrm{T}$ cells surrounded by a large number of $\mathrm{IgM}^{+} \mathrm{B}$ cells, as we had observed in untreated 10-month-old BXD2 mice (Fig. 5b, top). Characterization of the lymphocytes in the spleens of AdIL-17R:Fc-treated mice indicated a dissociation of $\operatorname{IgM}^{+} \mathrm{B}$ cells from $\mathrm{CD} 4^{+} \mathrm{T}$ cells and a dissociation of $\mathrm{B}$ cells (both $\mathrm{IgM}^{+} \mathrm{B} 220^{+}$and $\mathrm{IgM}^{-} \mathrm{B} 220^{+}$) from $\mathrm{CD}^{+} \mathrm{T}$ cells in the follicles (Fig. $\mathbf{5 b}$, bottom). Thus,

Figure 5 Disruption of GCs in BXD2 mice treated with AdIL-17R:Fc. (a) Percentage of GC (Fas ${ }^{\text {hi }}, \mathrm{PNA}^{+}$) B cells, gated for lymphocytes and $\mathrm{B} 220^{+}$cells, in adult (10-month-old) BXD2 mice treated with AdIL-17R:Fc or control AdLacZ ( $10^{9}$ virus particles per mouse, i.v.). The spleens were obtained $10 \mathrm{~d}$ after injection, and the percentage of GC B cells was determined as in Figure 4a. ${ }^{* *} P<0.01$. (b) Immunofluorescence microscopy of frozen sections of the spleens in a stained with anti-mouse CD4 (yellow), PNA (blue), anti-mouse IgM (red) and anti-mouse CD35 (white; left); or with anti-mouse CD4 (white), anti-mouse IgM (blue) and anti-mouse B220 (magenta; right). (c) RT-PCR analysis of Aicda, Rgs13, Rgs16, Rgs1, Cxcr4 and Gapdh mRNA in the spleens in a. Data are representative of three $(\mathbf{a}, \mathbf{c})$ or four $(\mathbf{b})$ experiments, or are the mean \pm s.e.m. of three independent experiments (a).

continued IL-17 signaling seems to be required to maintain the integrity of the GC structures and, specifically, to retain the B cells in close proximity to the $\mathrm{CD} 4^{+} \mathrm{T}$ cells. In the absence of IL-17, the B cells (mostly $\operatorname{IgM}^{+}$and to a lesser extent, $\operatorname{IgM}^{-}$) had dissipated.

Consistent with this concept, we observed downregulated expression of Rgs13 and Rgs16 mRNAs in the spleens of AdIL-17R:Fc-treated BXD2 mice (Fig. 5c; see Supplementary Table 2 for qPCR results). The downregulation of Aicda expression in the spleens of AdIL-17R: Fc-treated BXD2 mice (Fig. 5c and Supplementary Table 2 for qPCR results) further suggests that an interaction between $\mathrm{B}$ cells and CD4 ${ }^{+}$ $\mathrm{T}$ cells is required for upregulation of Aicda expression in the B cells ${ }^{15}$.

\section{Reduced GC formation in BXD2 $/ 17 r^{-I-}$ mice}

To determine whether the interaction of IL-17 with its receptor is associated with the increased humoral immune response in BXD2 mice, we backcrossed the $I l 17 r^{-1-}$ mice with $\mathrm{BXD} 2$ mice to produce BXD2 $I l 17 r^{-1-}$ mice with more than $99 \%$ of the BXD2 genome. Serum concentrations of IL-17 were threefold higher in 6-monthold BXD2 $I l 17 r^{-1-}$ mice as compared with the already enhanced abundance of IL-17 in wild-type BXD2 mice (Fig. 6a). The total cell count in the spleen of BXD2 $I l 17 r^{-l-}$ mice was significantly reduced $(P<0.05, n \geq 4$; Supplementary Table 1); on examination of the spleen, we found that, despite the high concentrations of circulating IL-17 in $I l 17 r^{-1-}$ mice, they showed less staining of $\operatorname{IgM}^{+} \mathrm{PNA}^{-}$B cells between the follicular dendritic cells and the marginal sinus than did wild-type BXD2 mice (Fig. 6b).

FACS analysis indicated that there were significantly lower percentages of $\mathrm{PNA}^{+} \mathrm{Fas}^{+} \mathrm{GC} \mathrm{B}$ cells in the spleens of 6-month-old $1 l 17 r^{-1-}$ BXD2 mice than in those of wild-type age-matched BXD2 mice (Fig. 6c). Quantitative imaging analyses showed that there were lower numbers and smaller areas of GCs in the spleens of 6-monthold $I l 17 r^{-1-}$ BXD2 mice as compared with age-matched wild-type BXD2 mice (Supplementary Fig. 2). By contrast, immunohistological analysis revealed that there was an increase in marginal zone B cells outside the marginal sinus area (Fig. $6 \mathbf{b}$ ), and that the percentage of $\mathrm{CD} 21^{\mathrm{hi}} \mathrm{CD} 23^{\mathrm{lo} / \text { neg }}$ marginal zone B cells was higher in $I l 17 r^{-1-} \mathrm{BXD} 2$ mice than in wild-type BXD2 mice, suggesting reduced migration of the $\mathrm{B}$ cells from the marginal zone to the follicular region (Fig. 6c). The IL-17-induced arrest of the B cell migratory response to CXCL12 or CXCL13 was not observed in B cells from $I l 17 r^{-1-}$ BXD2 mice (Fig. 6d), and administration of AdIL-17 did not induce the formation of GCs in $I l 17 r^{-1-}$ BXD2 mice (Supplementary Fig. 3 online). Thus, engagement of IL-17 with its receptor induces inhibition of the chemotactic response of B cells to CXCL12 and CXCL13.

Analysis of the RGS and chemokine mRNAs demonstrated lower expression of Aicda, Rgs13 and Rgs16 in the spleens of naive $I l 17 r^{-1-}$ BXD2 mice than in those of wild-type BXD2 mice, whereas the 


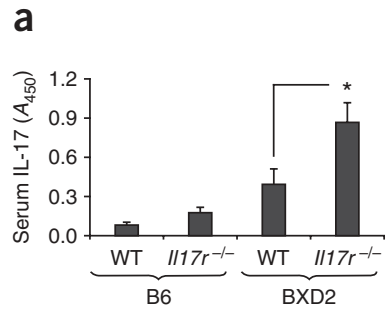

Figure 6 Reduced GC formation, Aicda expression and SHM in BXD2 $/ / 17 r^{-1-}$ mice. (a) ELISA of IL-17 in the sera of 6-month-old wild-type B6, B6 $/ 117 r^{-1-}$, wild-type BXD2 and BXD2 $/ 117 r^{-1-}$ mice. (b) Immunofluorescence microscopy of frozen sections of the spleens from 4-month-old wild-type BXD2 or $/ / 17 r^{-1-}$ BXD2 mice stained with PNA (blue), anti-mouse CD4 (yellow), anti-mouse IgM (red) and anti-mouse CD35 (white). MZ, marginal zone. Scale bar, $200 \mu \mathrm{m}$. (c) Percentage of $\mathrm{PNA}^{+} \mathrm{Fas}^{+} \mathrm{B}$ cells and percentage of recirculating follicular $\mathrm{CD} 21^{+} \mathrm{CD} 23^{\text {hi }} \mathrm{B}$ cells and nonrecirculating marginal zone $\mathrm{CD} 21^{\mathrm{hi}} \mathrm{CD} 23^{\mathrm{lo} / \text { neg }} \mathrm{B}$ cells gated within the $\mathrm{B} 22 \mathrm{O}^{+}$population in

6-month-old mice. ${ }^{*} P<0.05,{ }^{* *} P<0.01$ (see Supplementary Table 1 for the detailed analyses). (d) Chemotactic response of MACS-purified CD19 B cells from 3-month-old BXD2 $/ / 17 r^{-1-}$ mice to CXCL12 or CXCL13. Cells were cultured in the presence of mouse recombinant IL-17 (20 ng/ml) or vehicle for $4 \mathrm{~h}$, and then their migration in response to chemokine was analyzed after $2 \mathrm{~h}$. (e) RT-PCR analysis of the indicated mRNAs in 4-month-old wild-type and $/ / 17 r^{-1-}$ B6 and BXD2 mice (see Supplementary Table 2 for quantitative PCR analysis). (f) ELISA of anti-NP24 and anti-NP2 responses in NP-CGGimmunized 2-month-old wild-type and $/ / 17 r^{-1-}$ B6 and BXD2 mice. Mice were immunized intraperitoneally with $50 \mu g$ per mouse of NP-CGG, and the highaffinity and total NP-specific IgG2b and IgG2c responses were determined at day $21 .{ }^{*} P<0.05,{ }^{*} P<0.01$. (g) RT-PCR analysis of Aicda mRNA in immunized mice on day 21 (see Supplementary Table 2 for qPCR analysis). Data are representative of three (b-e,g) experiments, or are the mean \pm s.e.m. of five (a) or three (f) independent experiments.

abundance of Rgs1, Rgs2, Rgs10, Cxcr4, Cxcl12 and Cxcl13 mRNAs were comparable between the two strains (Fig. 6e and Supplementary Table 2). Comparison of the spleens of $I l 17 r^{-1-}$ B6 mice and wild-type B6 mice indicated a similarly altered pattern of gene expression. These results suggest that, in the absence of IL-17R, low expression of Rgs13 and Rgs16 mRNAs leads to a defect in the downregulation of chemokine responses that prevents spontaneous GC development.
Figure 7 Defective generation of autoantibodies and autoantibody-producing $B$ cells in the absence of IL-17R. (a) ELISA of IgM and IgG autoantibodies specific to DNA, histone or BiP in the sera of 4-month-old B6, wild-type BXD2 and $1 / 17 r^{-1-}$ BXD2 mice. Data are the mean \pm s.e.m. of four mice per group. ${ }^{*} P<0.05,{ }^{*} P<0.01$. (b) ELISPOT assay of the IgG isotype autoantibody-producing B cells from BXD2-GFP+ or BXD2- $/ / 17 r^{-1-} \mathrm{GFP}^{-}$mice. B cells enriched $\left(1 \times 10^{7}\right)$ from 2-month-old BXD2 $\mathrm{GFP}^{+}$mice were transferred into 2-month-old BXD2 $/ / 17 r^{-1-}$ mice. One day before transfer, recipient mice ( $n=4$ per group) were injected with AdIL-17 or AdLacZ ( $10^{9}$ viral particles per mouse). Three weeks after transfer, GFP ${ }^{+} / 117 r^{+/+}$BXD2 B cells or equal numbers of $\mathrm{GFP}^{-} 1 / 17 r^{-1-} \mathrm{BXD} 2 \mathrm{~B}$ cells isolated from the recipient GFP- $/ / 17 r^{-1-}$ BXD2 mice were sorted and cultured in vitro on ELISPOT plates coated with DNA, histone, BiP or collagen II. Bottom, mean \pm s.e.m. number of IgG autoantibody-forming spots. ${ }^{*} P<0.05$, $* * P<0.01$ for $/ 117 r^{+/+}$B cells with AdIL-17 treatment versus all other groups. (c) Flow

cytometry analysis of $\mathrm{PNA}^{+} \mathrm{Fas}^{+}$germinal center B cells from BXD2-GFP+ or BXD2-//17r-l- GFP- mice. Three weeks after transfer, single-cell suspensions prepared from the spleens of recipient GFP- $1 / 17 r^{-1-}$ BXD2 mice injected with AdIL-17 were analyzed for expression of Fas and PNA in populations gated on $\mathrm{GFP}^{+} \mathrm{B} 22 \mathrm{O}^{+}$cells for assessment of donor $/ 117 r^{+/+} \mathrm{B}$ cells or on GFP- $\mathrm{B} 220^{+}$cells for assessment of recipient $/ / 17 r^{-l-} \mathrm{BXD} 2 \mathrm{~B}$ cells. ${ }^{* * *} P<0.001$. Data are representative of five experiments or the mean \pm s.e.m. of two independent experiments. 
To determine how the absence of IL-17R affected antibody formation, we immunized $I l 17 r^{-1-}$ B6 and $I l 17 r^{-1-}$ BXD2 mice with the $\mathrm{T}$ cell-dependent antigen NP-CGG, which elicits a high-affinity response that can be measured by binding of the NP antibody to NP2-BSA-coated ELISA plates; this response can be compared with the total anti-NP response measured by binding of the antibody to NP24-BSA-coated ELISA plates. Because autoantibodies from BXD2 mice are mainly of the IgG2b and IgG2c isotypes, the anti-NP responses were determined in terms of these isotypes ${ }^{14,15}$. As compared with wild-type B6 mice, wild-type BXD2 mice showed enhanced high-affinity antibody production, as measured by the NP2-specific IgG2b and IgG2c responses on day 21 after immunization; and this antibody production correlated with higher expression of Aicda mRNA (Fig. 6f,g and Supplementary Table 2). The amount of $\mathrm{NP} 2$-specific IgG2b and IgG2c antibodies generated was significantly smaller in BXD2 $I l 17 r^{-1-}$ mice than in wild-type BXD2 mice, suggesting that the absence of IL-17R curtails the SHM associated with maturation of the antibody response.

\section{IL-17 orchestrates autoreactive GC development in BXD2 mice}

The total amounts of IgM, IgG2b and IgG2c immunoglobulins were equivalent or greater in BXD2 $I l 17 r^{-1-}$ mice as compared to wild-type BXD2 mice, suggesting that IL-17R is not required to maintain the total amount of antibodies in BXD2 mice (Supplementary Fig. 4a online). IL-17R may have a specific role in the production of autoantibodies, however, because the amounts of IgG anti-DNA, IgG anti-histone, and IgG and IgM anti-BiP (also known as $8-\mathrm{kDa}$ glucose-regulated protein (GRP78) or HSPa5) autoantibodies were lower in the serum of BXD2 $I l 17 r^{-1-}$ mice than in that of age-matched wild-type BXD2 mice (Fig. 7a). Both glomerular immune complex deposition and proteinuria were lower in BXD2-Ill7r-l- mice than in age-matched wild-type BXD2 mice (Supplementary Fig. 4b,c).

The reduction in the amounts of autoantibodies in the serum of BXD2 $I l 17 r^{-1-}$ mice might be due to direct attenuation of IL-17R signaling in the B cells, or it could be mediated indirectly through interference with the ability of IL-17 to enhance the concentrations of other systemic inflammatory factors. To distinguish between these possibilities, we introduced a green fluorescent protein (GFP) marker into the cells of the wild-type BXD2 mice by generating $\mathrm{GFP}^{+}$ transgenic BXD2 mice using a marker-assisted speed congenic approach. The B cells from the $\mathrm{GFP}^{+} I l 17 r^{+/+} \mathrm{BXD} 2$ mice were then sorted and transferred into BXD2 $I l 17 r^{-l-}$ mice. After 3 weeks, the spleens of the recipient BXD2 $I l 17 r^{-1-}$ mice were collected and the cells were sorted into $\mathrm{GFP}^{+} I l 17 r^{+/+}$and $\mathrm{GFP}^{-} I l 17 r^{-1-}$ B cells. Thus, in these experiments, the populations of $I l 17 r^{+/+}$and $I l 17 r^{-1-}$ cells were exposed to the same spleen microenvironments.

The numbers of $1 l 17 r^{+/+}$and $I l 17 r^{-1-}$ B cells producing DNA, histone and $\mathrm{BiP}$ autoantibodies were low in recipient $I l 17 r^{-1-}$ mice that had been given control AdLacZ (Fig. 7b). In contrast, in recipient $I l 17 r^{-1-}$ mice that had been given AdIL-17, the number of $I l 17 r^{+/+}$ $\mathrm{B}$ cells producing autoantibodies against DNA, histone and BiP was considerably higher than the number of autoantibody-producing $I l 17 r^{-1-}$ B cells. Under these conditions, only relatively few B cells produced autoantibodies to bovine collagen II, which was therefore used as an internal control (to assess the possible production of 'abnormal' autoantibodies, because naive BXD2 mice typically do not produce autoantibodies to this antigen) in these chimeric transfer experiments (Fig. 7b). The results showed that, in the same spleen microenvironment in which relatively large amounts of IL-17 and other cytokines were present, expression of IL-17R on the B cells was required for the development of autoantibodies characteristic of wildtype BXD2 mice (anti-DNA, anti-histone and anti-BiP, but not antibovine collagen II). In addition, we noted that 3 weeks after adoptive transfer of the $I l 17 r^{+/+} \mathrm{B}$ cells into the $I l 17 r^{-1-}$ mice that had been given AdIL-17, only $2 \%$ of the host $I l 17 r^{-1-}$ B cells had developed into $\mathrm{Fas}^{+} \mathrm{PNA}^{+}$GC B cells, whereas $17 \%$ of the donor $I l 17 r^{+/+} \mathrm{B}$ cells had developed into $\mathrm{Fas}^{+} \mathrm{PNA}^{+} \mathrm{GC} \mathrm{B}$ cells (Fig. 7c).

\section{DISCUSSION}

Our studies indicate that IL-17 has a previously unrecognized role in the generation of autoantibodies: IL-17 promotes the formation of GC structures and maintains them by modulating the effects of chemokines that regulate their formation. It is well established that chemokines have a pivotal role in the formation of GCs in that they attract $\mathrm{T}_{\mathrm{H}}$ cells and B cells to the GCs, they regulate movement of the B cells within the compartments of the GCs, and they help to determine how long the $\mathrm{B}$ and $\mathrm{T}$ cells are retained within the $\mathrm{GCs}^{27-29}$. Each of these activities is thought to influence the type of antibody response mounted by the $\mathrm{B}$ cells ${ }^{16-18}$. One of the most important chemokines in these events has been identified as CXCL12, which signals through the G-coupled protein receptor CXCR4 to regulate B cell migration and retention ${ }^{16,28,29}$. Rgs13 and Rgs16 transcripts are found in GC $\mathrm{CD}^{+} \mathrm{T}$ cells and in B cells, as are Rgs1 transcripts. Our data suggest that IL-17 affects CXC chemokine signaling by upregulating expression of the Rgs13 and Rgs16 genes in the B cells of autoimmune BXD2 mice. We found that IL-17 also downmodulated B cell migration in response to CXCL13, but the migration in response to CXCL13 was less than that observed in response to CXCL12. These data are consistent with previous results showing that RGS13- or RGS16induced inhibition of the CXCR4-CXCL12 signal results in arrest of the B cell migration ${ }^{29,32}$. Although 'knockout' of $R g s 1$ has been shown to enhance autoantibody production ${ }^{33}$, IL-17 did not seem to affect the expression of Rgs1 mRNA in the B cells of BXD2 mice.

Germinal center $B$ cells are in constant motion and migrate between the dark and light zones of the GCs ${ }^{18}$. Our analysis of the effects of induction of IL-17 suggests that expression of Rgs13 and Rgs16 can lead to the initial accumulation of B cells in GCs. We found that treatment with AdIL-17R:Fc, which blocks IL-17, results in loss of the association of $\mathrm{B}$ cells with $\mathrm{CD}^{+} \mathrm{T}$ cells, despite the continued clustering of $\mathrm{CD}^{+} \mathrm{T}$ cells. We further found that the absence of IL-17 signaling in $I l 17 r^{-1-}$ BXD2 mice resulted in not only a smaller GC response but also a lower ratio of follicular to marginal-zone $\mathrm{B}$ cells. These results indicate that IL-17 can function both to enhance the formation of new GCs and to stabilize the GCs once they have formed. Our results are consistent with the previously described association between the formation of autoreactive GCs (in which self-reactive $B$ cells receive prolonged nonspecific help from $\mathrm{T}$ cells) and the development of autoimmune disease ${ }^{34,35}$, and they suggest a mechanism by which this association might be mediated.

Our previous studies had indicated that enhanced Aicda activity that promotes SHM leads to the formation of highly pathogenic autoantibodies and thus represents an important pathogenic mechanism in autoimmune disease ${ }^{15}$. Increased SHM has been reported in $\mathrm{GCs}^{21,22}$; at sites external to the GCs, including the T-zone, red-pulp border of MRL-Fas ${ }^{\text {lpr/lpr }}$ mice $^{36,37}$ and marginal zone of NZM mice ; $^{38}$; and at ectopic sites ${ }^{20}$. We found here that treatment of B6 mice with AdIL-17 resulted in the development of GC B cells but not autoantibodies. This finding suggests that IL-17 modulates chemokine receptor signaling and is sufficient to induce GCs and to increase GC cell numbers. Alone, however, this process is not sufficient to promote autoantibody production in normal B6 mice that do not have other 
immune defects. This finding is consistent with our previous in vitro analysis showing that stimulation of $\mathrm{CD}^{+} \mathrm{T}$ cells from BXD2 mice with anti-CD3 plus anti-CD28 induces expression of Aicda in B cells from either B6 or BXD2 mice. By contrast, the coculture of stimulated $\mathrm{CD}^{+} \mathrm{T}$ cells from $\mathrm{B} 6$ mice and $\mathrm{B}$ cells does not induce detectable amounts of Aicda mRNA in the B cells from either B6 or BXD2 mice ${ }^{15}$. On the basis of our current results and previous observations, we propose that the proximity of CD86-expressing B cells to CD28expressing $\mathrm{CD}^{+}{ }^{+} \mathrm{T}$ cells in the GCs is the additional factor in BXD2 mice that leads to autoantibody production. Because we observed abnormally high abundance of Aicda expression in the follicular B cells of BXD2 mice ${ }^{15}$, we propose that increased $\mathrm{T}$ cell-B cell interactions, together with increased CD28-CD86 signaling within the GCs, leads to high Aicda expression and increased SHM.

Our data also show that, after immunization with a $\mathrm{T}$ celldependent antigen (NP-CGG), IL-17R signaling in B cells can promote an antibody affinity maturation response, as indicated by the significantly greater titers of high-affinity anti-NP antibodies in wildtype BXD2 mice than in either BXD2 mice lacking IL-17R or B6 mice that do not express high concentrations of IL-17R. In vivo neutralization of IL-17 by anti-IL-17 treatment in older BXD2 mice does not suppress IgM autoantibody-forming B cells but does suppress IgG autoantibody-forming B cells, which suggests that IL-17 is also important for B cell class-switch recombination in BXD2 mice (H.-C.H., J.W., P.A.Y., Q.W., J.C., J.D.M. et al., unpublished data). IL-17, however, does not stimulate the proliferation of B cells from BXD2 mice directly, and it does not enhance or diminish the kinetics of the B cell proliferative responses elicited by B cell receptor stimulation, LPS or CD40 signaling. This finding suggests that the development of a diverse spectrum of pathogenic autoantibodies in BXD2 mice is a two-step process that requires both enhanced $\mathrm{T}_{\mathrm{H}^{-17}}$ $\mathrm{T}$ cell lineage development and modulation of chemokine activity by IL-17 to promote spontaneous GC formation.

We found that the unfractionated spleen cells from BXD2 mice can develop efficiently into $\mathrm{T}_{\mathrm{H}^{-}} 17 \mathrm{CD}^{+}{ }^{+} \mathrm{T}$ cells, and this development occurs in the absence of exogenous IL-6 and IL-23. We observed enhanced production of IL- 6 and IL-23 by nonlymphoid cells in the spleen of BXD2 mice, suggesting that $\mathrm{T}_{\mathrm{H}^{-}} 17$ development is promoted by endogenous production of these cytokines. In the absence of IL-6 and IL-23, purified CD4 ${ }^{+} \mathrm{T}$ cells from BXD2 mice mainly polarized into IFN- $\gamma$-producing $\mathrm{T}_{\mathrm{H}} 1$ cells, which suggests that the greater polarization of $\mathrm{T}_{\mathrm{H}^{-}} 17$ cells from $\mathrm{BXD} 2$ mice was, for the most part, associated with the higher concentrations of Il6 and Il23 mRNA in the whole spleen mixture of cells rather than with a propensity of the $\mathrm{T}$ cells from BXD2 mice to polarize into $\mathrm{T}_{\mathrm{H}^{-}} 17$ cells. We have also found increased numbers of plasmacytoid dendritic cells (pDCs) that produce especially large amounts of IFN- $\alpha$ and IL- 6 in response to CpG-oligonucleotide in the spleens of BXD2 mice (J.W. and J.D.M., in unpublished data). CpG activation of pDCs has been proposed to lead to the development of autoantibodies by directly enhancing the B cell response $\mathrm{s}^{39,40}$. Our results suggest an alternative model in which $\mathrm{pDC}$ production of IL- 6 promotes the development of $\mathrm{T}_{\mathrm{H}^{-17}} \mathrm{~T}$ cells that produce IL-17 and are in close proximity to the $\mathrm{B}$ cells.

Our data suggest that enhanced $\mathrm{T}_{\mathrm{H}^{-}} 17$ activity, or the higher concentrations of IL-17 produced by these cells, can result in both the spontaneous generation of autoreactive GCs and the stabilization of autoreactive GCs. We propose a model in which IL-17 induces GC formation and the retention of B cells within the GCs through modulation of the activity of the RGS genes. The formation of the GCs and the retention of cells within them provide an optimal microenvironment for the upregulation of AICDA and the generation of pathogenic autoantibodies. The generation of Rgs13 and Rgs16 'knockout' mice on BXD2 background is currently ongoing, and targeted deletion of IL-17R on B cells may help to dissociate the proinflammatory effects of IL-17 from its autoreactive GC-promoting effects. The results of these studies should indicate whether therapies directed at either correcting the inhibitory effect of RGS proteins on G-coupled protein receptor signaling or specifically eliminating the autoreactive GC reactions associated with autoantibody production would be effective approaches for the treatment of autoimmune diseases.

\section{METHODS}

Mice. Female homozygous C57BL/6 and BXD2 recombinant inbred mice, and C57BL/6- $\mathrm{Tg}(\mathrm{UBC}-\mathrm{GFP}) 30 \mathrm{Sch} / \mathrm{J}$ transgenic mice were obtained from The Jackson Laboratory; B6 $I 117 r^{-1-}$ mice were obtained from Amgen. These mice were backcrossed with BXD2 mice for seven generations by a marker-assisted speed congenic approach with 146 markers ${ }^{41}$. All mice were housed in the University of Alabama at Birmingham (UAB) Mouse Facility under specific pathogen-free conditions in a room equipped with an air-filtering system. The cages, bedding, water and food were sterilized. All mouse procedures were approved by The UAB Institutional Animal Care and Use Committee.

Measurement of cytokines and cytokine-producing $\mathrm{T}_{\mathrm{H}}$ cells. The amounts of IL-17, IFN- $\gamma$, IL-4 and IL-6 in sera and cell-culture supernatants were evaluated with commercially available ELISA kits (Biosource International Invitrogen). Intracellular analysis of cytokines produced by $\mathrm{CD} 4^{+} \mathrm{T}$ cells was carried out by FACS analysis according to published protocols ${ }^{5,6}$. In brief, before carrying out intracellular cytokine staining, polarized whole spleen cells or purified $\mathrm{CD} 4^{+}$ $\mathrm{T}$ cells were stimulated for $5 \mathrm{~h}$ with phorbol myristate acetate (PMA; $50 \mathrm{ng} / \mathrm{ml}$; Sigma-Aldrich) and ionomycin (750 ng/ml; Sigma-Aldrich) in the presence of either Golgiplug (IFN- $\gamma$ and IL-17) or GolgiStop (IL-17 and IL-4) at the recommended concentrations (Pharmingen). Cells were stained extracellularly with fluorescein isothiocyanate-conjugated anti-CD4 ${ }^{+}$(clone RM4-5, Invitrogen), and then fixed and permeabilized with Cytofix/Cytoperm solution (Pharmingen) before intracellular staining with allophycocyanin-conjugated anti-IFN- $\gamma$ (XMG1.2) or anti-IL-4 (11B11), and phycoerythrin-conjugated anti-IL-17 (TC11-18H10). Samples were acquired with a FACSCalibur (Becton Dickinson), and data were analyzed with FlowJo or WinMDI software.

Frozen-section staining of GCs, and IL-17- and IL-17R-expressing cells. Spleens from mice were collected, embedded in Frozen Tissue Media (Fisher Scientific) and snap-frozen in liquid nitrogen. Frozen sections ( $7 \mu \mathrm{m}$ thick) were fixed in acetone for $15 \mathrm{~min}$ and dried in air for $30 \mathrm{~min}$. The sections were blocked with $5 \%$ horse serum for $30 \mathrm{~min}$ at room temperature $\left(22-28^{\circ} \mathrm{C}\right)$ and then stained for $30 \mathrm{~min}$ at room temperature with various antibodies. The following conjugations with Alexa fluor dyes (Invitrogen) were performed in accordance with the manufacturer's instructions: biotin-PNA (Vector Laboratory) to Alexa 350-streptavidin (Invitrogen), anti-mouse CD35 (clone 8C12, BD Bioscience) to Alexa 488; anti-IgM to Alexa 555; anti-CD4 (RM4-5, Invitrogen) to Alexa 488 or Alexa 647; anti-IL-17 (50101, R\&D Systems) to Alexa 555; and anti-IL-17R (AF448, R\&D Systems) to Alexa 488. Sections were mounted in Fluormount $\mathrm{G}$ (Southern Biotechnology) and viewed with a Leica DM IRBE inverted Nomarski/epifluorescence microscope outfitted with Leica TCS NT laser confocal optics. Unless stated otherwise, yellow represents Alexa 488 staining; blue, Alexa 350; red, Alexa 555; and white, Alexa 647.

RT-PCR. CD4 ${ }^{+} \mathrm{T}$ cells or B cells were purified from single-cell spleen preparations by using a positive selection column (Miltenyi Biotech). We routinely obtained $\mathrm{CD}^{+}$and B cells with $>98 \%$ purity by this method (Supplementary Fig. 5 online). RNA was isolated from $2 \times 10^{6}-10 \times 10^{6}$ cells by using Trizol reagent. The isolated RNA was converted to cDNA by a First Strand cDNA Synthesis kit (Fermentas). The primers, amplicon size and annealing temperature used for each gene are given in Supplementary Table 3 online.

B cell culture and proliferation assay. Single-cell suspensions were prepared from the spleens of mice aged 8-10 weeks. B cells were enriched by positive selection using magnetic anti-CD19 microbeads and an AutoMACS Magnetic Cell Sorter (Miltenyi Biotech). The purified B cells were cultured for $72 \mathrm{~h}$ at 
$37{ }^{\circ} \mathrm{C} / 5 \% \mathrm{CO}_{2}$ in triplicate wells $\left(5 \times 10^{5}\right.$ cells per well $)$ of a Costar 96 -well tissue-culture plate (Corning) in RPMI 1640 medium (Invitrogen) supplemented with $2 \mathrm{mM}$ L-glutamine, $25 \mathrm{mM}$ HEPES, $100 \mathrm{U} / \mathrm{ml}$ of penicillin, $100 \mu \mathrm{g} / \mathrm{ml}$ of streptomycin, $5.5 \times 10^{-5} \mathrm{M} \beta$-mercaptoethanol and 10\% FCS with or without different stimulators in the presence and absence of $20 \mathrm{ng} / \mathrm{ml}$ of recombinant mouse IL-17 (R\&D Systems) or $10 \mu \mathrm{g} / \mathrm{ml}$ of neutralizing antimouse IL-17 (R\&D Systems). Stimulators included $10 \mu \mathrm{g} / \mathrm{ml}$ of LPS (Escherichia coli 055:B5; Sigma-Aldrich), $10 \mu \mathrm{g} / \mathrm{ml}$ of anti-CD40 (HM40-3; Biolegend) and $10 \mu \mathrm{g} / \mathrm{ml}$ of $\mathrm{F}\left(\mathrm{ab}^{\prime}\right)_{2}$ goat-anti-mouse IgM ( $\mu$ chain, Jackson ImmunoResearch). The proliferative response was measured by a standard $\left[{ }^{3} \mathrm{H}\right]$ thymidine incorporation assay in which $1 \mu \mathrm{Ci}$ of $\left[{ }^{3} \mathrm{H}\right]$ thymidine (Amersham Biosciences) was added to each well during the last $12 \mathrm{~h}$ of culture. Cells were collected with a Filtermate harvester (Packard-Perkin Elmer), and radioactivity was measured with a TopCount liquid scintillation counter (Packard-Perkin Elmer).

$\mathrm{CD}^{+} \mathrm{T}$ cell isolation, polarization and expansion. $\mathrm{T}_{\mathrm{H}^{-}} 17$ cell polarization and expansion was carried out by published protocols $s^{5,6}$. In brief, spleens were collected from B6 or BXD2 mice, and single-cell suspensions were prepared by mechanical disruption in RPMI 1640 medium supplemented with $10 \%$ FCS, $100 \mathrm{IU} / \mathrm{ml}$ of penicillin, $100 \mu \mathrm{g} / \mathrm{ml}$ of streptomycin, $1 \times$ nonessential amino acids, $1 \mu \mathrm{M}$ sodium pyruvate, $2.5 \mu \mathrm{M} \beta$-mercaptoethanol and $2 \mathrm{mM}$ L-glutamine. $\mathrm{CD}^{+} \mathrm{T}$ cells were isolated using CD4 microbeads (Miltenyi Biotech). For stimulation of isolated $\mathrm{CD} 4^{+} \mathrm{T}$ cells, irradiated syngeneic splenic feeder cells (3,000 rad) were used as feeder cells, unless indicated otherwise, and were cultured with purified $\mathrm{CD} 4^{+} \mathrm{T}$ cells at a ratio of 5:1. Whole spleen cells or purified $\mathrm{CD} 4^{+} \mathrm{T}$ cells were activated with $2.5 \mu \mathrm{g} / \mathrm{ml}$ of anti-CD3 (clone 145-11, Biolegend). $\mathrm{T}_{\mathrm{H}}-17$ cells were differentiated and expanded for $5 \mathrm{~d}$ by the addition of TGF- $\beta(5 \mathrm{ng} / \mathrm{ml})$, anti-IFN- $\gamma(10 \mu \mathrm{g} / \mathrm{ml}$; clone XMG1.2) and anti-IL-4 (10 $\mu \mathrm{g} / \mathrm{ml}$; clone 11B11, Biolegend) in the presence or absence of IL-6 (10 ng/ml) and IL-23 (10 ng/ml).

Cell migration assay. Single-cell suspensions of spleen B cells from B6, BXD2 or BXD2-Ill7r ${ }^{-1-}$ mice that had been purified on an anti-CD19 MACS column (Miltenyi Biotech) were stimulated with medium either alone or with mouse recombinant IL-17 (20 ng/ml, R\&D Systems). The cell migration assay was carried out as described ${ }^{42}$. The stimulated cells $\left(2 \times 10^{6}\right)$ were loaded into the upper well insert $(8-\mu \mathrm{m}$ pore size) of a Transwell system $(5-\mu \mathrm{m}$ pore size; Costar), and either CXCL12 or CXCL13 was added to the bottom chamber at a final concentration of $100 \mathrm{ng} / \mathrm{ml}$. After incubation for $2 \mathrm{~h}$ at $37^{\circ} \mathrm{C}$ in a $5 \% \mathrm{CO}_{2}$ incubator, the cells that migrated were collected and resuspended in $300 \mu \mathrm{l}$ of FACS buffer (PBS containing $5 \%$ fetal bovine serum and $0.1 \% \mathrm{NaN}_{3}$ ). The cells that remained in the inserts or migrated to the lower chamber were counted by flow cytometry, and the distribution of the $\mathrm{CD}^{+}$or $\mathrm{B} 220^{+}$cells in terms of migrated and nonmigrated cells was determined. The chemotaxis index was calculated by dividing the number of cells that migrated in response to chemokine by the number of cells that migrated in the absence of chemokine ${ }^{32}$.

Administration of AdIL-17 and AdIL-17R:Fc. For the AdIL-17 producing high expression of IL-17 and the AdIL-17R:Fc that can neutralize IL-17 (refs. 43,44). AdIL-17 or AdIL-17R:Fc ( $10^{9}$ p.f.u. per mouse) was administered intravenously (i.v.) as described ${ }^{43,44}$.

Adoptive transfer of $\mathrm{GFP}^{+}$cells. Single-cell suspensions were prepared from the spleens of 2-month-old $\mathrm{GFP}^{+}$transgenic $I l 17 r^{+/+} \mathrm{BXD} 2$ mice. The spleen cells $\left(2 \times 10^{7}\right.$ in $200 \mu \mathrm{l}$ of PBS) were injected i.v. into the lateral tail vein of agematched $\mathrm{GFP}^{-} I l 17 r^{-1-}$ BXD2 mouse recipients that had been injected i.v. with either AdLacZ ( $10^{9}$ p.f.u.) or AdIL- 17 ( $10^{9}$ p.f.u.) $1 \mathrm{~d}$ before the adoptive transfer. Recipient mice were killed 3 weeks after the transfer. B cells were enriched from the spleens of recipient mice using an anti-CD19 microbeads (Miltenyi Biotech), stained with allophycocyanin-anti-B220 (clone RA3-6B2, Biolegend), and then sorted into $\mathrm{B} 220^{+} \mathrm{GFP}^{-}$or $\mathrm{B} 220^{+} \mathrm{GFP}^{+}$cells by FACS using a FACStar ${ }^{\text {plus }}$ instrument (Becton Dickinson). The sorted cells were then subjected to ELISPOT analysis.

ELISPOT quantification of autoantibody-producing B cells. To determine the frequency of autoantibody-producing B cells in the spleen, an ELISPOT assay was performed as described ${ }^{32}$ with modifications. Polyvinylidene difluoride-backed 96-well plates (Millipore) were coated overnight at $4{ }^{\circ} \mathrm{C}$ with $5 \mu \mathrm{g} / \mathrm{ml}$ of the indicated autoantigen, washed and then blocked with complete medium. BiP was purchased from Assay Designs; bovine type II collagen was purchased from Chondrex. B cells isolated from spleens of the mice were washed and adjusted to a final volume of $200 \mu \mathrm{l}$ containing $2 \times$ $10^{5}$ cells per well. After $4 \mathrm{~h}$ of incubation, cells were washed three times with PBS plus $0.05 \%$ Tween 20 before overnight incubation at $4{ }^{\circ} \mathrm{C}$ with $1 \mu \mathrm{g} / \mathrm{ml}$ of biotinylated goat anti-mouse IgG (Southern Biotechnology) in PBS plus $10 \%$ FCS. Plates were washed three times with PBS plus 0.05\% Tween 20, before $40 \mathrm{ng}$ of horseradish peroxidase (HRP)-conjugated goat anti-biotin (Vector Laboratories) in $100 \mu \mathrm{l}$ of PBS plus 10\% FCS was added to each well. Plates were incubated at room temperature for $1 \mathrm{~h}$ and washed first with PBS plus $0.05 \%$ Tween 20 and then with PBS alone before spots were developed with 3-amino-9-ethylcarbazole. Plates were read by an automatic ELISPOT reader (CTL) and analyzed with Immunospot 3.1 software (CTL).

Measurement of autoantibodies in sera. The reactivity of sera with different autoantigens was quantified by ELISA as described ${ }^{12,14,15}$. Each ELISA well was coated with $5 \mu \mathrm{g} / \mathrm{ml}$ of the test autoantigen. BiP was purchased from Assay Designs; bovine type II collagen was purchased from Chondrex; and all other protein autoantigens were purchased from Sigma-Aldrich. The assays were developed with an HRP-labeled isotype-specific goat anti-mouse (Southern Biotechnology) and tetramethylbenzidine substrate (Sigma-Aldrich). The absorbance at $450 \mathrm{~nm}\left(A_{450}\right)$ was measured with an Emax Microplate reader.

NP response and analysis. Mice were immunized intraperitoneally with $50 \mu \mathrm{g}$ of chicken $\gamma$-globulin haptenated with 4-hydroxy-3-nitrophenylacetyl (NP-CGG) (BioSearch Technologies) adsorbed to $1.3 \mathrm{mg}$ of alum (SigmaAldrich) in a total volume of $100 \mu \mathrm{l}$ of PBS. Sera were collected at the indicated times (before, and 7, 14 and $21 \mathrm{~d}$ after immunization). High-affinity anti-NP and total anti-NP IgG2b and IgG2 c were measured by ELISA using $\mathrm{NP}_{2}$-bovine serum albumin $\left(\mathrm{NP}_{2}-\mathrm{BSA}\right.$, a low hapten density to detect high-affinity $\mathrm{NP}$ antibodies) and $\mathrm{NP}_{24}$ - $\mathrm{BSA}$ (a high hapten density to detect both low- and highaffinity NP antibodies; Biosearch Technologies), respectively, as the target antigens ${ }^{45,46}$. IgG2b or IgG2c that bound to the plate was detected with an HRP-conjugated goat anti-mouse IgG2c or an HRP-conjugated goat antimouse IgG2b (Southern Biotech) and 3,3',5,5'-tetramethylbenzidine (Sigma) was used as the substrate. $A_{450}$ was measured on an Emax Microplate reader.

Note: Supplementary information is available on the Nature Immunology website.

\section{ACKNOWLEDGMENTS}

We thank Amgen for providing $I l 17 r^{-1-}$ B6 mice; E. Keyser and M.L. Spell (UAB FACS Core Facility) for operating the flow cytometry instrument; S. Williams (UAB High Resolution Imaging Facility) for acquiring confocal microscopic images; L. Harrington and C. Weaver for reagents and technical support in the $\mathrm{T}_{\mathrm{H}^{-}}-17$ polarization experiments; F. Hunter for review of the manuscript; and C. Humber for secretarial assistance. This work was supported by the Arthritis Foundation (H.-C.H.), the American College of Rheumatology program (J.D.M. and R.H.C.), VA Merit Review Grants (J.D.M and R.H.C.), Daiichi-Sankyo (J.D.M.), and the National Institutes of Health (R24 DK64400 to R.G.L.).

\section{AUTHOR CONTRIBUTIONS}

H.-C.H. and J.D.M. contributed to all studies; P.A.Y. was involved in all animal experiments, FACS staining, chemotactic experiments, and all qPCR and RT-PCR experiments; J.W., R.M., A.T., A.L.S., R.G.L. and R.H.C. contributed to all immunohistochemistry staining, imaging acquiring and imaging data interpretation; Q.W. contributed to animal experiments, FACS staining, chemotactic experiments, and ELISA and ELISPOT analyses; J.C. contributed to FACS analysis and adenovirus propagation; J.Y. contributed to $\mathrm{T}$ cell polarization experiments and chemotactic experiments; J.K.K. contributed to the generation of AdIL-17 and AdIL-17R:Fc; T.G., H.X. and R.W.W. contributed to the generation of $I l 17 r^{-1-} \mathrm{BXD} 2$ and $\mathrm{GFP}^{+} \mathrm{BXD} 2$ mice; T.-v.L.L. and D.D.C. contributed to the studies of SHM analysis.

Published online at http://www.nature.com/natureimmunology Reprints and permissions information is available online at http://npg.nature.com/ reprintsandpermissions

1. Kolls, J.K. \& Linden, A. Interleukin-17 family members and inflammation. Immunity 21, 467-476 (2004). 
2. Lubberts, E., Koenders, M.I. \& van den Berg, W.B. The role of T-cell interleukin-17 in conducting destructive arthritis: lessons from animal models. Arthritis Res. Ther. 7, 29-37 (2005).

3. Raza, K. et al. Early rheumatoid arthritis is characterized by a distinct and transient synovial fluid cytokine profile of T cell and stromal cell origin. Arthritis Res. Ther. 7, R784-R795 (2005)

4. Teunissen, M.B., Koomen, C.W., de Waal Malefyt, R., Wierenga, E.A. \& Bos, J.D. Interleukin-17 and interferon- $\gamma$ synergize in the enhancement of proinflammatory cytokine production by human keratinocytes. J. Invest. Dermatol. 111, 645-649 (1998).

5. Harrington, L.E. et al. Interleukin 17-producing $\mathrm{CD}^{+}{ }^{+}$effector T cells develop via a lineage distinct from the T helper type 1 and 2 lineages. Nat. Immunol. 6, 1123-1132 (2005).

6. Mangan, P.R. et al. Transforming growth factor- $\beta$ induces development of the $T_{H} 17$ lineage. Nature 441, 231-234 (2006).

7. Park, H. et al. A distinct lineage of CD4 T cells regulates tissue inflammation by producing interleukin 17. Nat. Immunol. 6, 1133-1141 (2005).

8. Komiyama, Y. et al. IL-17 plays an important role in the development of experimental autoimmune encephalomyelitis. J. Immunol. 177, 566-573 (2006).

9. Nakae, S., Nambu, A., Sudo, K. \& Iwakura, Y. Suppression of immune induction of collagen-induced arthritis in IL-17-deficient mice. J. Immunol. 171, 6173-6177 (2003).

10. Sonderegger, I. et al. Neutralization of IL-17 by active vaccination inhibits IL-23dependent autoimmune myocarditis. Eur. J. Immunol. 36, 2849-2856 (2006).

11. Taylor, B.A. et al. Genotyping new BXD recombinant inbred mouse strains and comparison of BXD and consensus maps. Mamm. Genome 10, 335-348 (1999).

12. Mountz, J.D. et al. Genetic segregation of spontaneous erosive arthritis and generalized autoimmune disease in the BXD2 recombinant inbred strain of mice. Scand. J. Immunol. 61, 128-138 (2005).

13. Wu, Y. et al. Synovial fibroblasts promote osteoclast formation by RANKL in a novel model of spontaneous erosive arthritis. Arthritis Rheum. 52, 3257-3268 (2005).

14. Hsu, H.C. et al. Production of a novel class of polyreactive pathogenic autoantibodies in BXD2 mice causes glomerulonephritis and arthritis. Arthritis Rheum. 54, 343-355 (2006).

15. Hsu, H.C. et al. Overexpression of activation-induced cytidine deaminase in B cells is associated with production of highly pathogenic autoantibodies. J. Immunol. 178, 5357-5365 (2007)

16. Allen, C.D. et al. Germinal center dark and light zone organization is mediated by CXCR4 and CXCR5. Nat. Immunol. 5, 943-952 (2004).

17. Allen, C.D., Okada, T., Tang, H.L. \& Cyster, J.G. Imaging of germinal center selection events during affinity maturation. Science $\mathbf{3 1 5}, 528-531$ (2007).

18. Schwickert, T.A. et al. In vivo imaging of germinal centres reveals a dynamic open structure. Nature 446, 83-87 (2007).

19. Walker, L.S. et al. Established T cell-driven germinal center B cell proliferation is independent of CD28 signaling but is tightly regulated through CTLA-4. J. Immunol. 170, 91-98 (2003).

20. Cassese, G. et al. Inflamed kidneys of NZB/W mice are a major site for the homeostasis of plasma cells. Eur. J. Immunol. 31, 2726-2732 (2001).

21. Luzina, I.G. et al. Spontaneous formation of germinal centers in autoimmune mice. J. Leukoc. Biol. 70, 578-584 (2001).

22. Nordstrom, E., Abedi-Valugerdi, M. \& Moller, E. Longevity of immune complexes and abnormal germinal centre formation in NZB mice. Scand. J. Immunol. 52, 477-482 (2000).

23. Wang, Y. \& Carter, R.H. CD19 regulates B cell maturation, proliferation, and positive selection in the FDC zone of murine splenic germinal centers. Immunity 22, 749-761 (2005)

24. Berman, D.M., Wilkie, T.M. \& Gilman, A.G. GAIP and RGS4 are GTPaseactivating proteins for the $G_{i}$ subfamily of $G$ protein $\alpha$ subunits. Cell $\mathbf{8 6}, 445-452$ (1996).
25. Koelle, M.R. A new family of G-protein regulators-the RGS proteins. Curr. Opin. Cell Biol. 9, 143-147 (1997).

26. Watson, N., Linder, M.E., Druey, K.M., Kehrl, J.H. \& Blumer, K.J. RGS family members: GTPase-activating proteins for heterotrimeric G-protein $\alpha$-subunits. Nature 383 172-175 (1996).

27. Estes, J.D. et al. Follicular dendritic cell regulation of CXCR4-mediated germinal center CD4 T cell migration. J. Immunol. 173, 6169-6178 (2004).

28. Moratz, C. et al. Regulator of $G$ protein signaling 1 (RGS1) markedly impairs $G_{i} \alpha$ signaling responses of B lymphocytes. J. Immunol. 164, 1829-1838 (2000).

29. Shi, G.X., Harrison, K., Wilson, G.L., Moratz, C. \& Kehrl, J.H. RGS13 regulates germinal center $B$ lymphocytes responsiveness to CXC chemokine ligand (CXCL) 12 and CXCL13. J. Immunol. 169, 2507-2515 (2002).

30. Armengol, M.P. et al. Chemokines determine local lymphoneogenesis and a reduction of circulating CXCR4 ${ }^{+} \mathrm{T}$ and CCR7 B and T lymphocytes in thyroid autoimmune diseases. J. Immunol. 170, 6320-6328 (2003).

31. Lubberts, E. et al. IL-17 promotes bone erosion in murine collagen-induced arthritis through loss of the receptor activator of NF- $\mathrm{\kappa B}$ ligand/osteoprotegerin balance. J. Immunol. 170, 2655-2662 (2003).

32. Han, J.I., Huang, N.N., Kim, D.U. \& Kehrl, J.H. RGS1 and RGS13 mRNA silencing in a human $B$ lymphoma line enhances responsiveness to chemoattractants and impairs desensitization. J. Leukoc. Biol. 79, 1357-1368 (2006).

33. Moratz, C., Hayman, J.R., Gu, H. \& Kehrl, J.H. Abnormal B-cell responses to chemokines, disturbed plasma cell localization, and distorted immune tissue architecture in Rgs1 $1^{-1}$ mice. Mol. Cell. Biol. 24, 5767-5775 (2004).

34. Munthe, L.A., Corthay, A., Os, A., Zangani, M. \& Bogen, B. Systemic autoimmune disease caused by autoreactive $B$ cells that receive chronic help from Ig $\mathrm{V}$ regionspecific T cells. J. Immunol. 175, 2391-2400 (2005)

35. Marion, T.N., Krishnan, M.R., Steeves, M.A. \& Desai, D.D. Affinity maturation and autoimmunity to DNA. Curr. Dir. Autoimmun. 6, 123-153 (2003).

36. Fu, Y.X. \& Storb, U. Immunology. Autoreactive B cells migrate into T cell territory. Science 297, 2006-2008 (2002).

37. William, J., Euler, C., Christensen, S. \& Shlomchik, M.J. Evolution of autoantibody responses via somatic hypermutation outside of germinal centers. Science 297, 2066-2070 (2002).

38. Duan, B., Croker, B.P. \& Morel, L. Lupus resistance is associated with marginal zone abnormalities in an NZM murine model. Lab. Invest. 87, 14-28 (2007).

39. Bave, U. et al. Fc $\gamma \mathrm{RII}$ a is expressed on natural IFN- $\alpha$-producing cells (plasmacytoid dendritic cells) and is required for the IFN- $\alpha$ production induced by apoptotic cells combined with lupus IgG. J. Immunol. 171, 3296-3302 (2003).

40. Meyers, J.A. et al. Blockade of TLR9 agonist-induced type I interferons promotes inflammatory cytokine IFN- $\gamma$ and IL-17 secretion by activated human PBMC. Cytokine 35, 235-246 (2006)

41. Williams, R.W. et al. Genetic structure of the LXS panel of recombinant inbred mouse strains: a powerful resource for complex trait analysis. Mamm. Genome 15, 637-647 (2004).

42. Moratz, C., Harrison, K. \& Kehrl, J.H. Regulation of chemokine-induced lymphocyte migration by RGS proteins. Methods Enzymol. 389, 15-32 (2004).

43. Schwarzenberger, P. et al. IL-17 stimulates granulopoiesis in mice: use of an alternate, novel gene therapy-derived method for in vivo evaluation of cytokines. J. Immunol. 161, 6383-6389 (1998).

44. Ye, P. et al. Requirement of interleukin 17 receptor signaling for lung CXC chemokine and granulocyte colony-stimulating factor expression, neutrophil recruitment, and host defense. J. Exp. Med. 194, 519-527 (2001).

45. Muramatsu, M. et al. Class switch recombination and hypermutation require activationinduced cytidine deaminase (AID), a potential RNA editing enzyme. Cell 102, 553-563 (2000)

46. Smith, K.G., Weiss, U., Rajewsky, K., Nossal, G.J. \& Tarlinton, D.M. Bcl-2 increases memory $\mathrm{B}$ cell recruitment but does not perturb selection in germinal centers. Immunity 1, 803-813 (1994). 